\title{
11 AGILITY THROUGH IMPLEMENTATION: A Case from a Global Supply Chain
}

\author{
Magnus Holmqvist \\ Volvo and Viktoria Institute \\ Göteborg, Sweden \\ Kalevi Pessi \\ Göteborg University and Viktoria Insititute \\ Göteborg, Sweden
}

\begin{abstract}
This case is based on sharing empirical experiences and results from several years of collaborative research. The focus is on implementation projects with solutions for spare parts distribution in the automotive industry.

The origin is a Volvo initiative with a Web portal for selling spare parts over the Internet. The journey will start with the creation of a platform for distribution of spare parts and continue with the process of introducing Web services and building new relations.

The new structure relies on the development of integration between legacy and a new information technology platform. The study followed the development of the platform as well as innovations that emerged in the new business structure. The paper describes the difficulty of creating a new platform and the event-more difficult establishment of new relations. However, the case also illustrates that continuous implementation projects deliver innovation in new relations and new channels, thereby displaying the unprecedented agility with which IT enables business value. The leverage for this is high and it is easier to roll out the new channels after the first implementation. Agility is achieved by working continuously with scenario development and by keeping implementation projects comprehensive, involving both technology and relations between supply chain actors.
\end{abstract}

Keywords Agility, implementation, IT management, supply chain, Web services 


\section{INTRODUCTION}

Agility is the ability to respond rapidly to unpredictable changes in demand. New technologies as well as business concepts have always been used to alter demand., but implementers need to be aware of the existence of considerable installed bases and existing relations. In-depth experiences from implementation projects in aftermarket logistics at Volvo provide unique knowledge of information technology and business development in a world that increasingly requires agility. Globalization and market demands have made logistics one of the most critical business issues. The case presents the active collaboration between the researchers and industry over a number of years. It summarizes and expands research presented earlier focusing on aftermarket logistics and theoretical scenarios (Holmqvist et al. 2001), the characteristics of e-business in logistics (Holmquist and Enquist 2001), actual e-business consequences for spare part distribution (Holmqvist et al. 2003), and process integration and Web services (Holmquist and Pessi 2005).

One objective of the case is to highlight results and experiences from business-tobusiness integration and how stakeholder relations, existing business, and IT context as well as endurance during implementation influence agility. The process illuminates how unforeseen and unintended results can be turned into valuable actions and innovations.

Theoretical reflections include IT management (Magoulas and Pessi 1998), systems development issues such as complexity of boundaries (Jackson 2003), and aspects of Web services such as composition and synchronisation (Christensen et al. 2001). Technology transfer and diffusion is a challenge, not least in terms of managing the duality of, first, exploring new technology then exploiting it in a global business context (Changsu and Galliers 2004; Finnegan et al. 2003; Huang et al 2003; these articles provide insights relating to agility from both the business and technology perspectives). Supply chain theories range from both supply to demand concerns (Ericsson 2003) and concepts from logistics that address agility (Christopher and Towill 2000).

We briefly describe the case context, followed by a summary of the research method. We then focus on specific implementation projects and their relation to agility. The paper concludes with comments on IT management and agility as delivered through implementation.

\section{CASE CONTEXT AND AFTER-MARKET LOGISTICS}

This case is anchored in the real business context of after-market logistics at Volvo, together with a perspective that has connections to current theories and research on IS/IT management. Volvo is a world-class provider of transport solutions, services, and products. With global presence and sales exceeding 170 billion SEK, its more than 70,000 employees focus on business-to-business operations in the areas of trucks, buses, construction equipment, marine and industrial engines, and Aero (www.volvo.com).

Logistics is a complex operation characterized by intensive information exchange between several stakeholders. Spare parts distribution at Volvo involves thousands of suppliers and tens of thousands of distribution points with hundreds of thousands of endcustomers. The industrial product families contain hundreds of thousands of parts, 
which demand handling with both a long-term service responsibility and complicated supersession chains.

The parts also increase in complexity, as they are no longer just physical but also digital as well as part of service arrangements and wider business solutions. The fierce competition in the transport sector pushes the business-to-business relations to focus on bottom-line results in a reality of diminishing margins. This at the same time that exploiting core competencies and finding new business propositions through innovations seems to be even more important.

IT management is not easy when there are highly dynamic factors. Multiple interrelations on the one hand and significant differences between actors on the other are common in the field of logistics. To be agile, have flexible yet not costly over capacity, is a term that has been used to describe a desired capability. In this sense, there is a similarity and natural attraction to the loosely coupled architecture that surrounds Web services. Web services are currently being widely addressed in IT management discussions.

Actual implementation experiences and results from advanced $\mathrm{Wcb}$ services are, so far, scarce. However, the commercial value and interest are vivid. For example, IBM is using one of the implementation projects within this case as a case study for Web services as well as presenting it in their "Company of the Month" section (http:/www306.ibm.com/software/ebusiness/jstart/casestudies/volvo.shtml)

Although IBM shares some of the project work from one specific implementation, it gives a simplified and commercialized view of the objective, the implementation itself and not the origin of the overall development. This case has the objective of sharing several implementations as well as enriching the context and highlighting challenges.

\section{RESEARCH METHOD}

The characteristics of this Volvo case are, in terms of size, scope, and content, relevant (Yin 1984). The in-depth knowledge and open access to the research context provides information that can contribute to a discussion of IS/IT management issues. The first author of this paper has an extensive background within Volvo, thus enhancing the relevance to practice. There is an advantage to having extensive access to the case context, a factor that is crucial when studying complex situations that need comprehensive descriptions.

This paper reports from the study of three implementation projects.

(1) Establishing platform and approaching truck dealers and end-customers in selected European markets

(2) Refinements for bus key customers and standalone truck importers

(3) Developments for truck dealers and end-customers in Asia and East Europe

The first specific Web service implementation project for this case originated in late 2001 and the third implementation was deployed during the spring of 2003. 
The methodology basically involves interpretive case study (Walsham 1995). In this case, the data collection has mainly been carried out through observations, semistructured interviews, and workshops with stakeholders, decision makers, designers, and developers. All implementation projects have involved interviews with the steering group chairman, the project sponsor, and the person in charge of the pilot site (these represent the $\mathrm{ClO}$, the after-market management, the dealer principal or equivalent). On several occasions, other representatives have been interviewed in order to include all supply chain actors.

User feedback from each implementation project has been collected and analyzed. As projects have been deployed, the first structured feedback has been conducted via a user satisfaction survey after three months and then continuously executed.

It may be argued that case studies in general lack replicability, that generalizations are difficult to make, that self-criticism is omitted, and that the research rigor is easy to question. However, the main objective of this case is to increase the understanding of agility and Web service implementation by sharing experiences of a practical context. The research in this paper is based on collaborative involvement and, together with a rigorous process, the objective is to provide contributions to both organizational development and scientific knowledge (Applegate 1999; Braa and Vidgen 1999; Mathiassen 2002).

We now present current developments and Web service implementations, reflecting on agility both in terms of technology and business.

\section{IMPLEMENTATION PROJECTS AND AGILITY}

The implementation projects that are the focus of this case originated in the review and development of an e-business strategy initiated in 2000. The business-to-business relations were challenged in many ways. Still, in a mature and large-scale industry, things do not change over night. Overall, the business-to-business relation is strongly driven by business focus rather than consumer behavior (i.e., productivity and bottomline results matter more than image and appearance). At the turn of the millennium, Volvo decided it was time to change their Internet solutions from being just a place on the Web where customers could find information about products and services into a tool for conducting business with customers and dealers.

A main driver for starting the project was a common view in the whole automotive industry that the Internet, as a new technology, enabled an opportunity to create a new, efficient channel to reach and conduct business with customers. Three main incentives were identified which justified the project.

- Competitors: other truck manufacturers but also new entrants. Special focus and attention was set on possible third party Internet companies that wanted to sell spare parts. This was a significant potential threat for the after-market business.

- Cost reductions: Internet and e-business could increase productivity in existing processes and improve support given to customers but especially to dealers with services like online training for mechanics, information and document distribution, and spare part look-up. 
- New services to broaden and expand the total offer such as simplified telematics services, load matching, and spare parts replenishment.

The result of the project was an initial implementation of two portals, one for customers and one for dealers. These portals include services on the Internet that support the customers' and dealers' total business cycle. This cycle ranges all the way from getting information about services and products, to being able to order spare parts (this service was called Parts Online and is a focus for this case), to operation and follow-up of the vehicle fleet, and, in the end, to resell, for example, an old truck. (The entry screens for the portal can be viewed at www.volvotrucks.com/onlineservices.) However, what can not be seen, and what was initially widely underestimated, was the challenge to establish the basic platform. The platform was part of the original implementation project and, therefore, the range of initial services that would support the total business cycle was limited. There was an awareness that establishment of a new channel with new technology would meet resistance and difficulties. Consequently, the goal was to include a valuable service in each part of the business cycle and expand gradually rather than to embrace everything at once. This was a major success factor, although the original implementation was generally regarded (especially in the first year) as too costly and delivering too little.

For Parts Online, the original goal was to increase sales to customers with accessories and consumable parts as well as spare parts for those customers operating their own workshop-within selected markets in Europe. Parts Online is a user-friendly system where customers can search for and order spare parts 24 hours a day, 7 days a week (24/7). An example of a screen from the Web portal is shown in Figure 1. Originally, the functionality was organized into categories of find parts, order parts, and use parts. However, as mentioned, in the original implementation, the functionality was rudimentary but has evolved gradually. The context was characterized by a lot of dynamics, thus the scope of the project was kept comprehensive in order to secure deliveries. At the same time, this created a situation where it would be possible to adapt rapidly to new issues. To be agile was characterized by one business manager as "the elephant cannot be a ballerina" and, on a follow-up question, he explained that the traditional strategic projects were usually like large elephants in order to give impact, but were not able to balance and fine tune during implementation.

The business value objectives in terms of cost reduction potential was realised, but the number of users was highly overestimated. Dealers saved time and had less administrative work on the phone with customers. A big issue was to solve the relation between dealers, customers, and Volvo where the main obstacle was to reassure the dealers that the solution was built to support their business and not to by-pass them. This was solved by letting the customer register and make the business agreement with a dealer and buy spare parts directly from them. During the implementation a concept of win-win-win arose, where a beneficial set-up for Volvo, the dealers and the customers could be designed.

One of the largest advantages that followed from keeping the initial implementation project limited was not only that it became comprehensive but also that much knowledge was gained from getting practical at an early stage. In combination with an initial value chain analysis and assessment actors, a number of theoretical scenarios had been developed. These scenarios have provided much of the knowledge base, contributing to an 


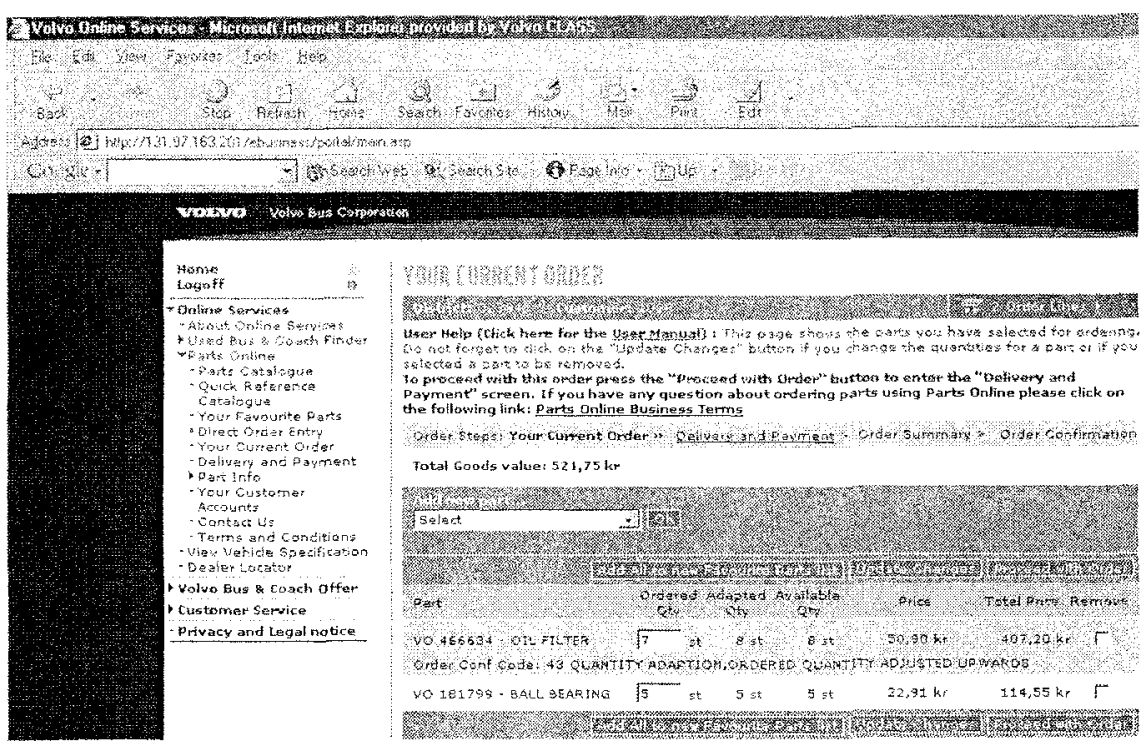

Figure 1. Example of the Web Portal Screen from Parts Online

architectural agility but ultimately leveraging the experiences gained during implementation in relation to follow-on projects. Four scenarios were developed for the imminent introduction of the online services project, including a spare parts portal as seen in Figure 2. The arrows show the physical distribution path based on the order flow and access to the customer order point, for example the "Today" scenario showed that there was no online connection between the dealer and end-customer workshop and consequently no management of the distribution between them (therefore the dashed arrow).

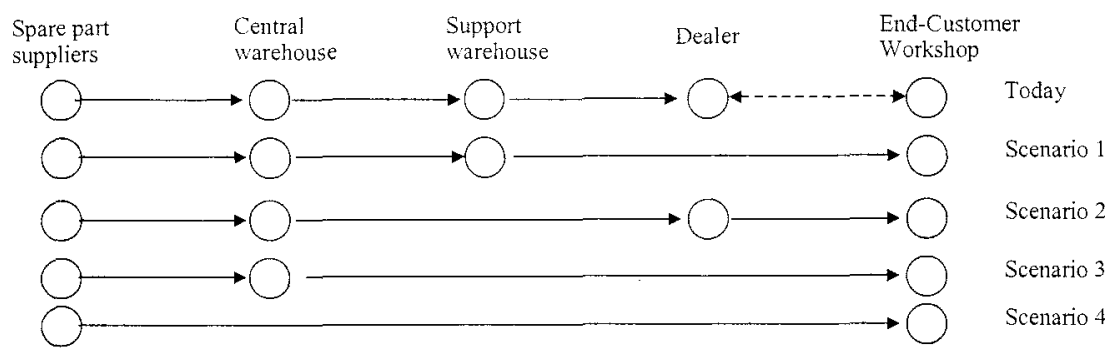

Figure 2. Original Scenario Development (Adapted from M. Holmqvist, O. Hultkranz, G. Stefansson, and A. Wingqvist, "Consequences of E-Commerce on Physical Logistics: A Theoretical Scenario for Spare Part Distribution," Proceedings of the $9^{\text {th }}$ World Conference on Transport Research, 2001) 
Scenario 1: The spare parts are distributed directly from the support warehouse to the end-customer, which is the customer's workshop in all scenarios.

Scenario 2: The spare parts are shipped directly from the central warehouse to the dealer and then from the dealer to the end-customer.

Scenario 3: The shipment is sent directly from the central warehouse to the endcustomer, bypassing both support warehouse and dealer.

Scenario 4: The spare parts are sent directly from the supplier to the endcustomer, bypassing all traditional distribution centers.

\subsection{Initial Implementation}

Volvo, similarly to other vehicle manufacturers, has come to play a major role in the after-market supply chain. Their dominating position originates from the control of product development and sourcing as well as influence upon the distribution network, dealers and customers. From the perspective of Volvo, the spare parts manufacturer represents the supplier from which spare parts are bought. Dealers are the actors that buy spare parts from the vehicle manufacturer and then sell them on to vehicle owners, thus they are sometimes also referred to as retailers. Consequently, vehicle manufacturers refer to vehicle owners and operators as customers or even end-customers who may have their own workshops.

The scenario analysis provided the original implementation project with a set of different possibilities. At that time, however, only one scenario had been justified for implementation. The most viable seemed to be to strengthen the relationship between the dealer and the customer by providing an additional channel for spare parts. Volvo would then also further build upon the relation with its dealers and, by improving the performance of the dealer offer, would gain in the competitive market place. This implementation reinforced an ultimate goal and overall business strategy intended to attract end-customers from their own workshops to the dealer workshops. Referring to the scenarios depicted above, this can be described as building upon Scenario 2 (as depicted in Figure 3 ).

The original implementation project provided the means to reach customers where the main impacts were the commercial relations, the technical platform, and extending the supply chain with delivery options as well as ordering systems to customers.

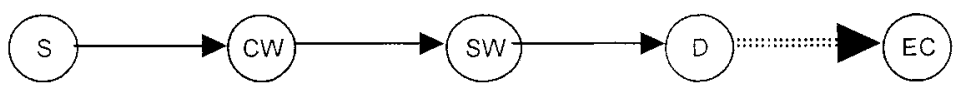

Figure 3. Original Implementation Project: Reaching End-Customers 
The technical challenges in deploying an infrastructure had mainly difficulties with single sign-on, multi-language, $24 / 7$, security, business process synchronization, and legacy connectivity. Nevertheless, the vast work did result in a platform that could actually be easily extended and respond in an agile way to increasing business demands with more functionalities to support the total business cycle.

This combined business and technology agility was a major benefit and, at the time, an innovation that would prove to deliver much more value than originally estimated. This would not have been possible without the first implementation. Furthermore, the first scenario had significant challenges with central involvement in very local relationships. Market companies and dealers as well as the global functions have not been used to collaborate in a cross-functional or cross-hierarchical way. Consequently, this is still an emerging area.

\subsection{Continuous Implementation and Innovation}

Even with the obstacles to overcome both in terms of technology and relations, the established platform provided opportunities for follow-on implementation projects. A second project was launched to deliver the enhanced technological features for a group of more-established relations: importers. Importers mainly exist in small markets on the international scene. They represent a company that usually sells to dealers and manages importation of spare parts.

The thought was also, in some rare and minor cases, to extend directly to endcustomers. However, still involving the close proximity and human relation of the dealers, the system and logistics connection goes from a central warehouse to endcustomers. This case would only be valid if certain criteria are fulfilled, such as endcustomers maintaining their own workshops for the foreseeable future and as long as distribution points and volumes are justifiable.

This first follow-on implementation, related to Scenario 3 and seen in Figure 4, enforced a win-win-win situation between end-customers, dealers, and Volvo. This was a profound innovation and a clear delivery of the existing agility. This has been a unique situation where global functions, market establishments, and dealers have collaborated both cross-functionally and between different levels. Furthermore, it has had a very high return in relation to the minor follow-on investment required.

After the second implementation, new possibilities were focused based on the positive results of the second project. Focus was put on new geographical areas out-side Europe, such as Asia, as well as extending the capabilities of support warehouses to

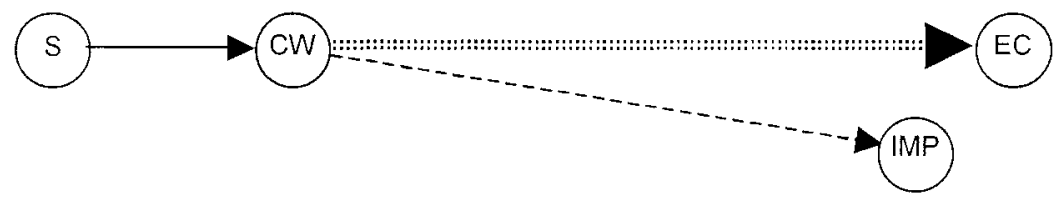

Figure 4. Continuous Implementation: Restructuring Relations 


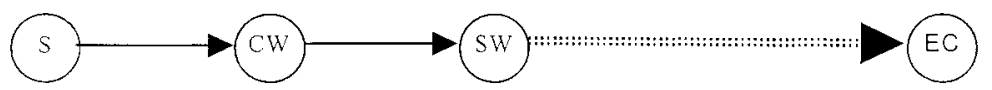

Figure 5. Continuous Implementation: Extending Reach

deliver to end-customers. Technically the platform needed minor adaptations and the objective was to extend logistical capabilities. Utilizing the capabilities leveraged agility and provided business value.

The second follow-on implementation (i.e., the third implementation project) correlates to Scenario 1 (see Figure 5). Based on the experiences gained during the first two implementations the challenge was to deploy a more decentralized structure (i.e., several support warehouses). This was possible to manage even though it required close analysis and monitoring during roll-out. Technically more-advanced Web services could be developed, primarily because a critical mass of practical competence had been built-up but also as platform stability was established. Still, difficulties were encountered, especially upon alignment for business process synchronization.

The overall impression about the development is that all the work that was completed during the initial implementation project paid off, gave payback in follow-on implementations. Both the cost and the lead-time were lowered in later versions. The largest benefits have been the agility that has enabled innovations both in terms of functionality and technical and business set-up as well as ability to manage relations between stakeholders. Table 1 provides a summarized view.

Table 1. Summarized View of Implementation Projects (Adapted from M. Holmquist, O. Hultkranz, G. Stefansson, and A. Wingqvist, "Consequences of E-Commerce on Physical Logistics: A Theoretical Scenario for Spare Part Distribution," Proceedings of the $5^{\text {ih }}$ Logistics Research Network Conference, 2003.)

\begin{tabular}{|c|c|c|c|}
\hline & $\begin{array}{c}\text { Original } \\
\text { Implementation }\end{array}$ & $\begin{array}{l}\text { First Follow-On } \\
\text { Implementation }\end{array}$ & $\begin{array}{l}\text { Second Follow-On } \\
\text { Implementation }\end{array}$ \\
\hline $\begin{array}{l}\text { Development Cost } \\
\text { (relative size) }\end{array}$ & 1 & $1 / 5$ & $<1 / 20$ \\
\hline Lead time (relative) & 1 & $1 / 2$ & $1 / 4$ \\
\hline \multicolumn{4}{|l|}{ Challenges } \\
\hline - Project process & $\begin{array}{l}\text { Complex, many } \\
\text { functions involved } \\
\text { - but good focus }\end{array}$ & $\begin{array}{l}\text { Easier, since } \\
\text { follow-on } \\
\text { learning curve }\end{array}$ & $\begin{array}{l}\text { Poor focus, since } \\
\text { less management } \\
\text { attention }\end{array}$ \\
\hline - Technology & New, Complex & Stabilizing & Established \\
\hline - Commercial relations & $\begin{array}{l}\text { Existing but new } \\
\text { collaboration }\end{array}$ & $\begin{array}{l}\text { Emerging but } \\
\text { new }\end{array}$ & $\begin{array}{l}\text { Experience from } \\
\text { former set-ups }\end{array}$ \\
\hline - Logistics & Not focused & New & Existing \\
\hline \multicolumn{4}{|l|}{ Resuits } \\
\hline - Cost/Benefit & Emerging & Great & As expected \\
\hline - Innovation & & $\begin{array}{l}\text { Win-win-win } \\
\text { relations }\end{array}$ & $\begin{array}{l}\text { Extended reach and } \\
\text { features }\end{array}$ \\
\hline
\end{tabular}


Before providing some concluding comments, it must be emphasized that no general governance model for agility will be delivered. At the most, the scenario development may been seen as a guideline but, due to the business dynamics, it will not be possible to strictly control strategic developments. Thus thoughts of strategic alignment (Henderson and Venkatraman 1993) are too inhibiting while, at the same time, just allowing drift (Ciborra 2000) may lose the ability to drive progress.

Consequently, agility is nurtured by action through implementation, based on a strategic awareness, and with comprehensive projects it is possible to lead development.

\section{CONCLUDING COMMENTS}

The new structure for spare parts distribution at Volvo relies on the development of integration between legacy and a new IT platform as well as development of relationships between stakeholders. The case shows that implementation projects on a solid platform designed to meet agile business demands bring innovations that have enabled a new business structure.

The creation of a new platform is problematic and the establishment of new relations is even more difficult. The main challenges are: single sign-on, process synchronization, multi-language, 24/7, security, and legacy connectivity. However, areas that have been less illuminated are single sign-on and business process synchronization and these are highlighted here as a main concern. Consequently, they are presented as areas for further research.

Finally, this case has summarised but also expanded findings from research that has been presented in earlier papers. It is important to see the continuation of results through a holistic review of IT management. Specifically, continuous implementation projects can deliver innovation in new relations and new channels, especially when agility has been addressed from the beginning. It is easier to roll out the new channels after the first implementation; it is beneficial to start in areas where established relations exist, it is favorable to wait with development of advanced Web services until the technical platform is stable and key business relations are established-then the leverage constitutes the agility that provides a high business value.

Agility is achieved by working continuously with scenario development and by keeping implementation projects comprehensive. These involve both technology and relations between supply chain actors.

\section{REFERENCES}

Applegate, L. "Rigor and Relevance in MIS Research-Introduction," MIS Quarterly (23:1), Special Issue, March 1999, pp. 1-2.

Braa, K., and Vidgen, R. Interpretation, Intervention, and Reduction in the Organizational Laboratory: A Framework for In-Context Information System Research," Accounting Management \& Information Technologies (9), 1999, pp. 25-47.

Changsu, K.. and Galliers, R. "Deriving a Diffusion Framework and Research Agenda for WebBased Shopping Systems,"Journal of Electronic Commerce Research (5:3), 2004, pp. 199215. 
Christopher M, Towill D. "Supply Chain Migration from Lean and Functional to Agile and Customized," Supply Chain Management (5:4), 2000, pp. 206-213.

Christensen, E., Curbera, F., Meredith, G., and Weerawarana, S. "Web Services Description Language (WSDL) 1.1," WC3 Note, Ariba, International Business Machines Corporation. and Microsoft, March 15, 2001 (available online at http://www.w3.org/TR/2001/NOTEwsdl-20010315).

Ciborra, C. (Ed.). From Control to Drift, Oxford: Oxford University Press, 2000.

Ericsson D. "Supply/Demand Chain Management: The Next Frontier for Competitiveness," in Global Logistics, D. Waters (Ed.), London: Kogan Page, 2003.

Finnegan, P., Galliers, R., and Powell, P. "Applying Triple Loop Learning to Planning Electronic Trading Systems," Infonmation Technology and People (16), 2003 pp. 461-483.

Henderson, J., and Venkatraman, N. "Strategic Alignment: Leveraging Information Technology for Transforming Organizations," IBM Systems Journal (32:1), 1993, pp. 4-16.

Holmqvist, M., and Enquist, H. "IT Is Not New vs Old, Yet Real e-Logistics," in Proceedings of the $24^{\text {th }}$ IRIS Conference, Bergen, Norway, 2001, pp. 445-458.

Holmqvist. M., Hultkrantz, O., Stefansson, G., and Wingqvist, A. "Consequences of ECommerce on Physical Logistics: A Theoretical Scenario for Spare Part Distribution," in Proceedings of $9^{\text {th }}$ World Conference on Transport Research, Seoul, Korea, 2001.

Holmqvist, M., Hultkrantz, O., Stefansson, G., and Wingqvist, A. "Consequences of ECommerce for Spare Part Distribution," in Proceedings of $5^{\text {th }}$ Logistics Research Network Conference, London, 2003, pp. 196-216.

Holmqvist, M., and Pessi, K. "Process Integration and Web Services," Scandinavian Journal of Information Systems, 2005 (forthcoming).

Huang. J., Makoju, E., Newell, S., and Galliers, R. "Opportunities to Learn from 'Failure' with Electronic Commerce: A Case Study of Electronic Banking," Journal of Information Technology, (18), 2003, pp. 17-26.

Jackson, M. Systems Thinking: Creative Holism for Managers, New York: John Wiley \& Sons, 2003.

Magoulas, T., and Pessi K. Strategisk IT-management, Ph.D. Thesis, Göteborg University, 1998.

Mathiassen, L. "Collaborative Practice Research," Scandinavian Journal of Information Systems (14), 2002, pp. 57-76.

Walsham, G. "Interpretive Case Studies in IS Research: Nature and Method," European Journal of Information Systems (4), 1995, pp. 74-81.

Yin, R. Case Study Research: Design and Methods, Thousand Oaks, CA: Sage Publications, 1984.

\section{ABOUT THE AUTHORS}

Magnus Holmqvist (M.Sc.) is an Industrial Ph.D. candidate at the Göteborg University and currently works with Business Innovation at Volvo Information Technology (www.gu.se, www.volvo.com). He has extensive experience with global supply chain management, specializing in after-market business. Magnus' research interests are in the integration of complex systems and he has been a frequent guest lecturer in subjects such as business process development and project management. Magnus can be reached at Magnus.Holnqvist@volvo.com.

Kalevi Pessi (Ph.D.) leads the Business Technology research group at the Viktoria Institute (www.viktoria.se). He is head of the IT Management Master's program at the IT University in Göteborg (www.ituniv.se). Kalevi's Ph.D. thesis was in IT management; his current research interests are in the areas of business value and architectural design. He has been the managing director of the Viktoria Institute and Knowledge Management Director at Guide, a large Swedish consultancy firm, and has broad experience from trade and industry. Kalevi can be reached at pessi@informatik.gu.se. 